\title{
Postmodernism and Language in Sam Shepard's True West and Tooth of Crime
}

\author{
Bahar Mehrabi (Corresponding author) \\ Faculty of Foreign Languages, Shiraz University \\ Eram Square, Faculty of Humanities, Shiraz University \\ Tel: 98-831-4241128Ｅ-mail:Bahar.Mehrabi@yahoo.com
}

\author{
Dr. Parvin Ghasemi \\ Associate Professor, English Literature, Faculty of Foreign Languages, Shiraz University \\ E-mail: Pghesemi2000@yahoo.com \\ Mehdi Abbasi \\ English Department, Fars Science and Research Branch, Islamic Azad University, Fars, Iran \\ E-mail: Mehdiabbasi24@gmail.com
}

Received: 18-06- 2012

doi:10.7575/ijalel.v.1n.4p.131
Accepted: 18-07- 2012

Published: 01-09- 2012

\begin{abstract}
Sam Shepard has gained a reputation as one of America's foremost living playwrights. In over forty plays, Shepard has broken down traditional notions of dramaturgy in combining both modernist notions of the absurd and familiar icons from the American cultural landscape with an energy tinged by anarchy and violence. Moreover, Shepard has been considered by many critics as a postmodern dramatist. Hassan (1987) piles up a lengthy list of artists from various disciplines whose names epitomize postmodernism for him. The playwrights are: Samuel Beckett, Eugene Ionesco, Harold Pinter and only Sam Shepard and August Wilson from America. One characteristic of postmodern literature in general, is a focus on the instability of meaning and the inadequacy of language to completely and accurately represent truth, along with an irony and playfulness in the treatment of linguistic constructs. In other words, there is a questioning of language as a medium of perception and communication. Language can name the pain but it can't be the pain; language cannot reach the actual individual feeling. Language is not strong enough to convey the intense emotion. In postmodern poetics, there is a paradigmatic shift from the idea that language is transparent to the disclosure of its physicality, its intimacy, its obdurate persistence, and its paradoxical fragility. Thus, language is an insufficient means for transforming the ideas that exist in one's mind. The aim of the present article would be to present the ways in which the dramatic language of Sam Shepard, as a postmodern drama, demonstrates inadequacy of language in communication. In order to reach this goal, however, a number of his early dramas will be brought under scrutiny with regard to their language and style from the postmodern point of view.
\end{abstract}

Keywords: Fragmentation, Postmodernism, Language, Grand Narratives, American Drama

1. Introduction

The plays of Sam Shepard have always been concerned with the problem of identity crisis of the modern man. Shepard's dramatic universe is a complicated and largely unhappy place where characters suffer extraordinary anxiety due to the instability and inauthenticity of the world which surrounds them. In short, they are on guard against lies fed to them by the media. Shepard and many of his characters endeavor to defend themselves against the weight of the past and the anxiety of the present by searching out a deeper, more essential origin (or origins) through which to establish a viable identity.

The characters that he brings on stage are depicted as fragmented selves who cannot thoroughly communicate their inner selves through language, which in a postmodern sense proves to be an inadequate means of 
communication. In a postmodern traditional way of thinking, a person's sense of identity is a composite constructed by the forces of the surrounding culture. Individual consciousness--a vague, "decentered" collection of unconscious and conscious beliefs, knowledge, and intuitions about oneself and the world--is malleable and arrived at through interaction with the surrounding culture. Postmodernism then, in stark contrast to modernism, is about the dissolving of the self. From the postmodernist perspective, we should not think of ourselves as unique, unified, self-conscious, autonomous persons. Such could be viewed in a number of his plays, including his early play concerning the broken life of two rock stars; Tooth of the Crime, and his later play called True West, which designates the fragmented life story, as well as the pains resulting from lack of communication between two typically American brothers.

The present article is an attempt to demonstrate the inadequacy of language as a means of communicating the inner selves of the characters in the two plays of Sam Shepard; True West and Tooth of the Crime. Therefore, first an attempt will be made to define the postmodern fragmented identity as the basis for the lack of communication in the plays. After the fragmented identity of the characters is discussed, the inadequacy of language is demonstrated in the dialogues between the rock stars and the brothers.

\section{Discussion}

Postmodernism, as a chain of thought in general, which has influenced a number of disciplines such as philosophy, religion and literature, has also manifested its effective features in the theatrical works after the Second World War. Jean-François Lyotard begins to lay out some of the developments of what he calls "the postmodern condition" in his book by that name, and offers a condensed definition of postmodernism as simply "incredulity toward meta-narratives" (xxiv). Where the modernist literary tradition has come to be seen by postmodernist theorists as "totalizing" discourse that characteristically ties all details into an artistic unity, postmodern literature often presents its ideas and its meanings through fragmentation and disruption of continuity.

In addition to a theoretical perspective, the term postmodern is often used to describe the condition of living in contemporary, post-industrialized societies with the stance of questioning truth and authority that such a condition precipitates. Connor (2004) has engaged in a remarkable and detailed analysis of the development of the postmodern through various stages explaining throughout the difficulties in defining the notion. His summery is instructive:

Having expanded its range and dominion hugely during the first period of separate accumulation in the 1970 s and the syncretic period of the 1980 s, the idea of the postmodern began for the first time to show its rate of expansion during the 1990s. . . B By this time, 'postmodernism' has also entered the popular lexicon to intensify a loose, sometimes dangerously loose, relativism. . . . So, whereas postmodernism had expanded its reach in academic discussion, it had shrunk down into a casual term of abuse in more popular discourse. (Connor, 2004, p. 5)

Most interpreters of postmodernism assume that there is a clear cut difference between the modern era and the postmodern era. The modern era is the period that began in the late 17th century and ended sometime in the 1960 s; the postmodern is the last 30 years or so. Glass (1995) affirms such definition of postmodernism by stating that: "Postmodernism is a philosophy that has reacted strongly against several assumptions of modernity: those concerning progress, history, causality, system, absolutes, meanings, the unitary self, technological judgment, and conformity" (p. 1).

Many say that one main difference between the two eras has to do with the question of unity, wholeness, and totality. In the modern era people wanted some kind of totality: a unified conception of the world, a unified set of values, a unified culture and lifestyle, etc. Some modern people actively searched for such totality. Others no longer expected to find such unity, so they didn't really look for it. But they still missed it and regretted its loss. So modern people had nostalgia for pre-modern times, when unified totality was possible, and they wished that they too could have this wholeness in their lives. However, the postmodern does not mention these notions as such, there is no unity, and thus it cannot be achieved at all.

Christopher Butler (2002, p. 5) has summarized the characteristics of the postmodern as described by the critics:

By the mid-1960s, critics like Sontag and Hassan had begun to point out some of the characteristics, in Europe and in the United States, of what we now call postmodernism. They argued that the work of the postmodernists was deliberately less 
unified, less obviously masterful, more playful or anarchic, more concerned with the process of our understanding than with the pleasures of artistic finish or unity, less inclined to hold a narrative together, and certainly more resistant to a certain interpretation.

In such a non-coherent world, the postmodern has also been associated with the criticism of language. The languages of our culture (the verbal and visual signs we use to represent the world to ourselves) literally "construct" what we think of as "real" in our everyday existence. In this sense, reality is a "text" or "composite" of texts and these texts are the only reality we can know. Our sense of self--who we are, how we think of ourselves, as well as how we see and interpret the world and give ourselves meaning in it--is subjectively constructed through language. As Saddik (2007) states:"Characteristics of postmodern literature and drama include a focus on the instability of meaning and the inadequacy of language to completely and accurately represent truth, along with an irony and playfulness in the treatment of linguistic constructs"(p. 6).

Finding a basic determined definition for any literary term is not an easy task. Whether we categorize the literary works as to their genres or the period in which they have been produced, there would be still a sense of uncertainty. Naturally this difficulty prevails in the attempt to define the term 'Postmodern Drama'. The shift from Modern to Post-Modern Theatre is one of the most interesting and controversial developments in theatre history. Western theatre, for more than 2000 years, has addressed the meanings of social and philosophical issues, but with the shift into Post-Modernism theatre now in addition also it addresses the meaning of "meaning" itself, and how society constructs (or fails to construct) meaning - through our interactions with each other and our interactions with our history which lives through us.

Though the characteristics of postmodern thought can best be found among the novels and long fiction in general, the other literary genres of poetry and drama have also been influenced by the postmodern debates. Schmidt $(2005$, p. 10) rightly affirms that theatre, even more than any other genre can yield to postmodernist features. She states that" It is precisely because of drama's idiosyncratic notion of authorship that it expresses postmodern notions well enough".

What is generally called the 'Postmodern Drama' is characterized by a number of features which make it distinguishable from the modern drama or even the Avant Guard movement in drama of the early decade of the twentieth century. Having been formed basically after the 1960s, the so-called postmodern drama is, as Steve Conner (1997) states "often dated from the upsurge of performance art during the decade of 1960s, with its happenings, spectacle, dance, theatre and... Which sought to free performance from its degrading subservience to the pre-existing script"(p. 143).

Moreover, the postmodern drama, besides all its specific features, is concerned with the inadequacy of language as a means of communication, as is the case with any other forms of postmodern literature, such as poetry or novel or fiction in general. Defining this lack of function of language in postmodernism is possible, if one compares and contrasts this element with modernism. . In modernism, language or the mode of expression used in producing and disseminating knowledge must be rational also. To be rational, language must be transparent; it must function only to represent the real/perceivable world which the rational mind observes. There must be a firm and objective connection between the objects of perception and the words used to name them (between signifier and signified). Modern societies depend on the idea that signifiers always point to signified, and that reality resides in signified. In postmodernism, however, there are only signifiers. The idea of any stable or permanent reality disappears, and with it the idea of signified that signifiers point to. Rather, for postmodern societies, there are only surfaces, without depth; only signifiers, with no signified.

To generalize the roles of language, several points should be made clear throughout the history of rhetoric to demonstrate the development of the thoughts about language. Plato wrote of rhetoric, the animosity he held toward the Sophists, and how rhetoric of "empty speech" stands apart from true and valuable knowledge. The study of the philosophy of language through men like Wittgenstein discusses how words build "knowledge-making" and how language shapes our thoughts. Nietzsche argued the death of God and moral code, ultimately heralding the death of meaning of language. Postmodern thought and the post-structuralism within postmodernism argues that language has no meaning apart from other language which is subjectively defined by the listener. Barthes heralded the "Death of the Author." Hermeneutics investigates the process of the interpretation of meaning and can include both verbal and non-verbal meaning of communication.

Modernism centered on certain truths, that which rested primarily upon the optimism of both the Enlightenment (faith in reason and science) and in Hegel's idea of the Unity of all Knowledge (man's evolutionary process of 
growth of the mind from ignorance into total being). These ideas were defined as the grand narratives that shaped our secular culture throughout most of the 20th Century. Inevitably, modernism rendered itself quite limited and unable to solve humanity's problems, proving it to be just another futile means of man establishing himself as his own salvation. But according to men like the postmodern theorist Lyotard, the Enlightenment failed miserably, and science also proved that it was not a universal constant. Neither could really lead us to total truth and the grand, transcendent narratives proved to be limited, so Lyotard and the postmodernists abandoned objective truth in favor of a new strategy: disbelief in the truth of grand narratives by replacing it with the subjective use of language and media to prop up subjective ideas about purpose, meaning and truth.

Hence, a postmodern man is empowered to question the validity of any rules, theories and conventions as he is constantly confronted with a shifting environment, speed changes and an accelerated rhythm of life. As trapped in this world, man can no longer attain a unified identity, but is rather a fragmented existent. It is obvious that such an identity can no longer communicate through the language the characteristics of which was discussed earlier as an 'inadequate mean' for communicating the ideas of the fragmented selves in the postmodern world.

Most of the critics unanimously believe that there is no more individuality, in the postmodern society. The self is no more the united whole of the modern era, but rather a constructed fragmented phenomenon which is basically under the dominance of mass media images. As Katz \& Rice (2002) state the postmodern self is "a series of unrelated episodes that connect to the society only through disciplinary sanctions that limit the self and dominate it politically" (p. 226). According to Løvlie (1992, p. 119) the postmodernist "does not go for identity but for the manifold and equivocal". The strategy implied in this statement pertains to the de-socialization of the subject. In other words, the postmodern self is released from the fixed relationship between nominal identity and social roles. Freedom is found not in the pursuit of authenticity but in the interplay of multiple roles that signify the openness of all meanings. The self is no longer defined as a consistent conglomeration of attitudes and perceptions strung together by the power of reason.

Among the post war American dramatists, the one which could be discussed as manifesting certain postmodern features in his dramas, besides David Mamet, is obviously Sam Shepard. Most of the plays of the American playwright Sam Shepard are basically concerned with the problem of identity. From his early experimental plays like Suicide in B Flat, or Mad Dog Blues up to his later more realistic plays, the prominent themes of his plays are identity crisis as well as the regeneration of American Western myths. However, his later plays known as family plays mostly deal with the realistic depiction of the situation of normal American family life, and the effect of family in the formation of one's identity. Quite a large number of critics have accounted the importance of Sam Shepard with regard to his new way of dramaturgy. Innes (1993) puts him in one category with O'Neill and says "Like O'Neill almost half a century earlier, Shepard's early plays are characteristic of the avant-grand"(p. 218).

During his whole career, Sam Shepard has always been involved in the matters of searching for one's identity. The characters that he brings to the stage are shown in the struggle to find their final image of self and they are entangled in the web of society and their family. Gilman (1981) in his introduction to the collection of seven plays of Sam Shepard sums up his most frequent themes in his plays as agreed by most of his critics. He asserts that Shepard has been hailed by many as the best living American playwright, and he has also been receiving detraction by only a few. He says: "The majority of his plays deal with one or more of these matters; the death or the betrayal of the American Dream, the decay of our own national myths, the growing mechanization of our lives, the search for roots, and the travail of the family"(xi). Furthermore; he adds that the "Identity and roots merge as themes in Sam Shepard"(Gilman, 1981, xxii).

Mottram (1984) in his book entitled Inner Landscapes; the Theatre of Sam Shepard mainly concentrates on Shepard's early plays including his family plays and investigates the role of myth and culture in his plays. He believes that Shepard's work is "rich in images from myth, history and contemporary reality"(Mottram, 1984, p. 25). By exerting the society and its various aspects in his works, Mottram (1984, p. 34) believes, Shepard is able to "explore the simultaneous alienation and integration of the individual". Sam Shepard appears to be attempting to stage the fragmentation of identity in the present situation of man, as living in a postmodern era. Sam Shepard, one of the greatest canonical, yet refusing to accept the canon, American dramatists demonstrates a great concern with the identity crisis that is the prominent characteristics of the postmodern era.

As Shepard is liable to fall into the category of postmodern dramatist, it is possible to acknowledge the concept of language in his plays, and the way that language functions, or fails to function, in the realm of communication, as postmodern characteristics. This specific sort of treatment with the identity or individuality of 
the characters as displayed in the plays of Sam Shepard is one of the basic ways of postmodernism in his theatre. As was stated earlier, the postmodern man bears a split self which is characterized by his searching for roots, the history which is long far gone. As Heauve (1993, p. 208) explains: "Unable to reclaim the origins of their crisis and perhaps what preceded it, the characters are cut off from their pasts and left to survive in a world where the only viable alternative is to reconstitute themselves in the present".

The sense of being lost from history is also a reason related to the effect of the society in the shaping of the split self in the pair characters of Sam Shepard's plays. The characters are depicted as being trapped in the web of the west which has exerted a lot of influences upon them, as it is manifested in their double, split self. In other words as Carveth (1993) states: "The personal and interpersonal dilemmas of the contemporary disordered self pervade the work of the American playwright, Sam Shepard" (p. 19).

The two brothers in Shepard's True West provide the best examples of the problematic dual identity of the postmodern era. As Williams (1997) asserts, in all of his plays, Shepard's hero is a "nowhere man who has willingly abandoned a sense of time, place and history"(p. 57). Further, by focusing on the character of Lee in True West, she asserts that Shepard's persona "Challenges the percept behind the postmodern theory which assumes that contemporary man's loss of subjectivity and history must necessarily be a negative experience" (Williams, 1997, p. 58).

Lee and Austin represent two kinds of ways that the modern man behaves; Austin tries to cling to the past by having the eagerness of going to the desert with his brother and he shows his nostalgia and eagerness to get back to the family roots, but he fails. Lee is the other type who is ready to encounter the free land. These behaviors are due to the fact that, according to Fredrick Jameson, the modern man has lost his sense of past and place; thus, his private identity has totally vanished. Such a man will reach hallucinatory relation with the others in search of his past.

It is evident, thus, that the dramatic characters in the plays of Sam Shepard demonstrate a strong sense of being lost from history and the past which is no more the cohesive war, basically as a result of war. In Malkin's words (1999): "Shepard is not seriously concerned with the past as history. Rather, he seeks to display the erasure of a collective identity through the total commoditization of mythic memory" (p. 24). The search for identity, has long been of primary importance to Shepard, and is evident in the way the two brothers, Austin and Lee in his True West, the two rock stars in the Tooth of the Crime and Eddie and May in Fool For Love are lost in their sense for history. Bottom (1998, p. 191) states;

Austin and Lee, May and Eddie; are bound together in dualistic, complementary pairs, each character appears to represent one side of a double headed coin. Yet as ever in Shepard's work, duality leads not to a healthy balance, but to perpetual division. ... These pairings are both interdependent and self destructive, caught in an impossible bind of mutual incompatibility.

In addition to the two brothers in Shepard's True West, the character of Crow in his Tooth of the Crime is also postmodern in the way he has no definite sense of past or that of history. Malkin $(1999$, p.129) believes that this character is "Shepard's fully imagined embodiment of postmodern ethic and style". Moreover, the two Rock Stars who are the central characters of his Tooth of the Crime both seem conflicted with regard to their history, as it is evident in the refrain between the two ". . . here's another illusion to add to your confusion. . . ". This line does not belong to a specific scene of the play; rather it is frequently heard throughout the play.

Having been lost from any connection to the past, the brothers in True West as well as the two rock stars in Tooth of the Crime demonstrate a fragmented identity, the one which does not bear any specific image of its own entity, thus cannot communicate through the inadequate language which cannot wholly transform the inner fragmented self of them. As such, most of the time, the words are non-referent signs, which might ultimately end in struggle. There is no specific idea communicated. The characters do not agree with one another as a result, and then there comes even a fight between the two, as in evident constantly in Tooth of the Crime, the play in medias res where Hoss, the former rock star is so shattered with his identity that he is to attempt suicide.

The same process of repulsion and attraction is evident in True West. Lee in the True West is a desert resident. He has lived in the desert for five years and he is now back, but still he is yearning for the times he has spent in the desert. As such, he is a sort of outcast, who has lost any sense of what the old values could mean. This is evident in his comment on the antiques that their mother keeps at home in Scene 2. 
Demastes (1988) believes that in True West "Shepard dramatizes these 'identities' by illustrating the disjunctive nature of human personalities subjected to a soul-less culture"(P. 108). In other words, Shepard matches this fragmented identity staged in this play to the society in which the characters live. The 'real, new west', as he calls it, is depicted in this play as "-the West of temporary living, full freeways, and empty hearts. It is the 'West' where the present and the future are everything. The past means nothing". (Demastes, 1988, p. 111) He also confirms that in this play the struggle is non- ending, leading to nowhere: "The play does not advocate victory of one side over the other, but neither does it totally advocate a peaceful co-existence, sensing that such an event is impossible. Rather, the true West is one that occupies a psychological frontier within each self where the struggle should exist continually and by existing guarantees life itself" (Demastes, 1988, p. 114).

Shepard's settings are often a kind of nowhere land on the American Plains and his characters are typically loners and drifters caught between a mythical past and the mechanized present, and his works often concern deeply troubled families. As Patraka and Siegel (1985) observe" Shepard observes that, in our essentially material and profane culture, we have desacralized the past and seem unable to replace our old legends with any viable new ones" (p. 5).

The language, in the two plays by Sam Shepard, Tooth of the Crime and True West, is not the modern language as referring to a unified reality outside, and thus; communicating the ideas as they go on in the mind of the 'unified' characters who either hold an identity or are, at least searching for that. Having been labeled as 'postmodern' the dramas of Sam Shepard demonstrate the fragmented identity of the postmodern man who is trapped in the web of society and family. As such, the dialogues, in the two plays fail to transfer the meaning. The lack of communication can therefore justify the overall pattern of attraction and repulsion between Hoss and Crow in Tooth of the Crime and Lee and Austin in True West, which ultimately changes into a fight between the two.

It appears that the process of repulsion and attraction is present from the very beginning of the conversation between the brothers. The paradox that exists in the words of Lee with regard to his relationship with Austin is important to note here. In Act I scene I when Austin is offering Lee to choose another neighborhood because he is afraid, Lee might "get picked up," Lee's response suggests two opposite things. He tries to convey that Austin is also like not a "regular looking" trying to suggest that Austin resembles Lee. However, a few lines later, he apparently rejects any close affinity with his brother, saying "Yer not gonna' have to worry about me! I've been doin' alright without you. I haven't been anywhere near you for five years! Now isn't that true?" (Shepard, p. 24). The discrepancy of the spoken words demonstrates the inadequacy of language as a means of communication.

\section{Conclusion}

Shepard's success in writing plays which are deeply concerned with the American as well as the universal crisis of identity of man, along with the disappearance of the myths and the roots that link us to the past, is clearly unavoidable. The particular human condition with which Shepard is most familiar, his own, seems to be the model for his characters' arc of enactment, assessment, and disillusionment fueled by an anxiety that the exercise might prove fruitless and false as well as the hope that it might somehow ring true. He could be categorized as a postmodern dramatist who is concerned with the fragmented identity of man in the postmodern era. His plays, specifically Tooth of the Crime and True West stage the fragmented identities of Hoss and Crow, and Austin and Lee respectively. Holding such an identity, the characters appear to suffer from lack of communication. This is due to the inadequacy of language as a means of communication defined within the postmodern poetics. The dialogues between the mentioned characters demonstrate the inadequacy of language in the way they end in fight.

\section{References}

Bottoms, S. J. (1998). The theatre of Sam Shepard: states of crisis. Cambridge: Cambridge University Press.

Butler, Ch. (2002). Postmodernism a very short introduction. Oxford: Oxford University Press.

Carveth, L. (1993). "The Borderline dilemma in Paris, Texas; psychoanalytic approaches to Sam Shepard." Canadian Journal of Psychoanalysis, 1(2), 19-46.

Connor, S. (Ed.). (2004). The Cambridge companion to postmodernism. Cambridge: Cambridge University Press. 


\section{International Journal of Applied Linguistics \& English Literature}

ISSN 2200-3592 (Print), ISSN 2200-3452 (Online)

Vol. 1 No. 4; September 2012

Conner, S. (1997). Postmodernist culture: an introduction to theories of the contemporary. London: Blackwell Publishing Company.

Demastes, W. M. (1988). Beyond naturalism: a new realism in American theatre. New York: Greenwood Press.

Glass, J. M. (1995). Shattered selves. Cornell: Cornell University Press.

Hassan, I. (1987). Toward a concept of postmodernism. In The postmodern turns. Columbus: Ohio University Press.

Innes, Ch. (1993). Avant grade theatre (1892-1992). London: Routledge.

Katz, J. \& Rice, E. (2002). Social consequences of internet use; access, involvement, and interaction. Illinois: MIT Press.

Løvlie, L. (1992). Postmodernism and subjectivity. In S. Kvale (Ed.), Psychology and postmodernism (PP. (119-134). London: Sage.

Malkin, J. R. (1999). Memory Theater and postmodern drama. Michigan: University of Michigan Press.

Mottram, R. (1984). Inner landscapes; the theatre of Sam Shepard. Missouri: Colombia University of Missouri Press.

Patraka, M, \& Siegel, M. (1985). Sam Shepard. Idaho: Boise State University Printing and Graphics Services.

Saddik, J., Halliwell, M., \& Mosley, A. (2007). Contemporary American drama. Edinburg: Edinburg University Press.

Schmidt, K. (2005). Theatre of transformation. New York: Rodopi Press.

Heauve, M. V. (1993). Performing drama / dramatizing performance. Michigan; University of Michigan Press.

Williams, M. (1997). Nowhere man and the twentieth century cowboy; images of identity and American history in Sam Shepard's 'True West'. Modern Drama, 40(1), 57-73. 